\title{
The lived experience of CrossFit as a context for the development of women's body image and appearance management practices
}

\author{
Miranda Podmore and Jennifer Paff Ogle*
}

\author{
*Correspondence: \\ Jennifer.Ogle@colostate.edu \\ Department of Design \& \\ Merchandising, Colorado \\ State University, Mail Delivery \\ Code 1574, Fort Collins, CO \\ 80523-1574, USA
}

\begin{abstract}
The purpose of this interpretive study was to explore how women's participation in the sport of CrossFit sets a context for the development of their body images-including their thoughts and feelings about the body and their lived experiences of embodiment-as well as their perceptions of culturally constructed ideals of beauty and gender. Analyses were informed by feminist cultural studies. In-depth, face-to-face interviews were conducted with 16 women who regularly participate in CrossFit. Data were analyzed using constant comparison processes. Findings illuminate how women experienced the culture of a male-owned, co-ed, CrossFit gym and how their immersion and participation in that gym culture gave rise to varied bodily experiences and practices, including body/appearance ideals, bodily appraisals, appetites and diets, physical fitness ideologies, appearance management routines, perspectives on gender, and identity development. Participant narratives revealed diverse lived realities across accounts as well as some evidence of contradiction or ambivalence within individual accounts. Implications for professionals who work in the body image area (e.g., nutritionists, counselors/therapists, sports psychologists), for the apparel and merchandising industry, for the sport of CrossFit, and for future work in the area are discussed.
\end{abstract}

Keywords: Athlete, Body image, CrossFit, Female, Women

\section{Introduction}

Identified as one of the "fastest growing sports in America" (Rishe 2012, para. 5), CrossFit is a high-intensity fitness regimen that combines aerobic exercise, gymnastics, and weight training (Ritter 2014) and that emphasizes ten different fitness domains: strength, agility, flexibility, power, speed, stamina, accuracy, balance, endurance, and coordination (Glassman 2002, para. 1). The CrossFit fitness movement was established in 2000 by Greg Glassman, who founded the fitness company, CrossFit, Inc., in Santa Cruz, California. Today, CrossFit has grown to encompass over 13,000 affiliated gyms and more than 100,000 accredited CrossFit Level 1 trainers/coaches (CrossFit, Inc. 2014b, para. 3, 2017, para. 3). Representing a $\$ 4$ billion business (Ozanian 2015), CrossFit attracts both men and women in equal numbers, with $42 \%$ of participants aged between 25 and 34 years (Rally Fitness 2017). 
Within the CrossFit community, individual (i.e., affiliate) CrossFit gyms are referred to as "CrossFit boxes" (Tao 2012, para. 2). Affiliate gyms or boxes are not franchises, per se, but are licensors of the "CrossFit" name and are similar in terms of fitness programming and certification requirements for the coaches (Washington and Economides 2015). CrossFit workouts (referred to as "workouts of the day" or "WODs") are posted on CrossFit Inc's daily blogs. Although affiliates may develop their own WODs, those developed by the national headquarters may, at times, be used as benchmarks to assess participants' progress (Glassman 2003). WODs differ slightly for male and female participants (e.g., in terms of prescribed weights and exercise movements) and are promoted as being "inclusive" for all "committed individuals," meaning that they can be adjusted to the specific abilities or needs of participants (CrossFit, Inc. 2014a, para. 6; "What is CrossFit?" 2012, para. 3). In recent years, CrossFit curriculum has expanded to include education on varied topics, ranging from Olympic weight-lifting to self-defense (CrossFit, Inc. 2014c, para. 3).

With the present work, we were interested in exploring how women's participation in CrossFit sets a context for the development of their body images-including their thoughts and feelings about the body and their lived experiences of embodiment (cf., Grogan 2008) - as well as their perceptions of culturally constructed ideals of gender and beauty. CrossFit's unique ideological underpinnings position it as a compelling sport community to consider relative to women's body images and to cultural gender norms that prescribe how women ought to behave and appear. As we discuss, prior work suggests that the culture of the CrossFit transmits rather contradictory messages about gender to its participants, at once challenging and supporting ideal femininity/female beauty as defined within Western cultures (Knapp 2015a; Washington and Economides 2015). To date, however, little is understood about how immersion within this complex and multifaceted sport culture may shape women's embodied experiences and practices.

\section{Literature review}

\section{Feminist cultural studies}

Researchers have invoked feminist cultural studies to consider how gender and culture impact women's immersion with sport (e.g., Hall 1996; Markula 1995; McDermott 2000). This framework, which draws upon cultural studies and feminist theory, explores the role of gender within culture, where culture is understood to include everything from diet to dress to language and daily activities (Lovell 1995). Gender is regarded as socially constructed, learned behaviors and expectations (Andersen 1997) that are linked to biological maleness or femaleness. In turn, maleness is associated with masculinity and femaleness with femininity (Bartky 1990).

Feminist cultural studies provides an apt framework for considering cultural representations of the body that set a context for women's lived experiences. Although there are multiple forms of femininity within the contemporary western cultural context, sociocultural pressures exhort women to present a privileged or hegemonic form of femininity that emphasizes heterosexual romance and that places value on women's appearances (Krane et al. 2004; Ussher 1997). Hegemonic femininity shapes Western cultural ideals of female beauty by promoting a singular ideal that sets unattainable and contradictory standards for women's appearance such as the notion that women should be thin but 
curvaceous; small-hipped but large breasted; and fit and toned, but not overly muscular (Bordo 2003; George 2005; Markula 1995). White, heterosexual, physically-able bodied women who conform to this demanding cultural beauty ideal are valued, whereas women who violate these expectations are viewed as inferior (Holliday and Hassard 2001) and may end up feeling inadequate and unattractive (Bartky 1988; Markula 1995).

Feminist cultural studies also has been adapted to understand the "paradox of the physically active female body" (Krane et al. 2004, p. 316; see also Cole 1993). The paradox suggests that, because sports are defined as masculine, female athletes must develop characteristics in line with masculinity (e.g. competiveness, muscularity) to succeed in their chosen sports. However, presenting more masculine characteristics conflicts with socially acceptable femininity (Krane 2001; Krane et al. 2004), even in spite of some movement toward a more toned or muscular feminine ideal in recent years (George 2005). Hegemonic femininity allows women very narrow "margins of acceptability" relative to their gendered presentations of self (Krane 2001, p. 118). As such, female athletes often find themselves in a position where they must balance characteristics necessary for success in their sport with those that are needed to construct an "appropriate" presentation of femininity. This, the paradox suggests, can be rather challenging for female athletes.

\section{Body image among female athletes}

Women's involvement in sports has given rise to a diverse array of embodied experiences. Some female athletes develop a dislike for the muscular physiques they develop as a result of their athletic participation (George 2005; Howells and Grogan 2012). Other evidence suggests that women who participate in sports regard fat as not only unattractive, but as inhibiting of their athletic performance (George 2005). This perception is consistent with findings that, compared to non-athletes, female athletes are at higher risk for body dissatisfaction and/or disordered eating (Greenleaf et al. 2009), frequently controlling their weight through dieting, fasting, and excessive exercising (Anderson and Petrie 2012; Crissey and Honea 2006; George 2005). Female athletes participate in lean sports and non-lean sports. Lean sports are those where weight and appearance are viewed as central to athlete success. Non-lean sports are those where weight and appearance are less essential to athlete success. Researchers have found that women who participate in both lean and non-lean sports are "at risk" for lowered body satisfaction and/or eating disordered symptomatology (e.g., Anderson and Petrie 2012; Milligan and Pritchard 2006).

Contradicting these findings, several researchers have found that women's athletic participation decreases the risk for body dissatisfaction and problematic eating, including eating disorder symptomatology (DiBartolo and Shaffer 2002; Smolak et al. 2000). Compared to adolescent girls participating in stereotypically feminine sports, those participating in stereotypically masculine sports have been found to be at a lower risk for developing body dissatisfaction and for engaging in dieting for purposes of weight loss (Crissey and Honea 2006). Participating in varied sports may support other "body positive" experiences, providing women a foundation to privilege their bodily strength and function over their bodily aesthetics and to enjoy the physicality of their sport (Eklund and Masberg 2014; Krane et al. 2004). And, for female athletes, building strength, 
muscularity, and athletic skill has been found to be experienced as a source of confidence and empowerment (e.g., George 2005; Eklund and Masberg 2014; Howells and Grogan 2012; Krane et al. 2004).

To some extent, social context helps to explain female athletes' varying experiences of the body; although some female athletes may feel confident in themselves and their bodies while in a specific sporting realm, in non-sporting situations, they may feel that their bodies "stand out" and violate social norms (Beckner and Record 2016; George 2005; Howells and Grogan 2012; Steinfeldt et al. 2013). A variety of others factors can further explain contradictory findings related to how women's athletic participation shapes their body-related feelings and behaviors. As noted above, the particular sport in which a female athlete is involved may place her at more or less risk for body-dissatisfaction or disordered eating, with participation in stereotypically gendered sports offering some protection to female athletes against negative body experiences (Crissey and Honea 2006). Competitive level of sport participation also has been identified as a possible explanation for differences across findings, with elite athletes facing more pressure to perform, and consequently, more risk for eating problems (Anderson and Petrie 2012; Smolak et al. 2000). In fact, in one study, competitive level was cited as a factor explaining the unexpected finding that female non-lean sport athletes were at greater risk for body dissatisfaction and eating disorders as compared to female lean sport athletes. Here, the researchers noted that the female lean sport athletes competing in Division I collegiate sports likely already had a thin physique, and thus, were not striving to attain this body type (Milligan and Pritchard 2006).

\section{CrossFit research}

\section{Analyses of CrossFit promotional literature}

CrossFit promotional literature may reflect and transmit the culture and ideology of the sport to those who participate in it, and thus, is important to consider. In one analysis of this literature, Washington and Economides (2015) explored how CrossFit constructs its "ideal" woman by analyzing CrossFit videos uploaded to CrossFit's YouTube channel as well as content from the social media accounts of top-performing female CrossFit athletes. Although limited content highlighted bodily performance over aesthetics, at its core, the authors argued that CrossFit promotional literature largely emphasized an "attractive body, rather than a strong, functional one" (p. 8).

Knapp (2015a) analyzed gender representations within CrossFit Journal, a free publication available to subscribers through the CrossFit website, concluding that the Journal content both reinforced and challenged ideal (i.e., hegemonic) femininity. Findings revealed that women were less frequently represented in the CrossFit Journal as compared to men, possibly constructing the sport as the preserve of men. Women also were shown in the Journal wearing (and occasionally working out in) traditionally feminine attire, feminizing, and in some cases, objectifying, them and maintaining norms of ideal femininity. In other situations, the hegemonic feminist ideal was visually disrupted. For instance, after the 2007 CrossFit games (an annual fitness competition sponsored by CrossFit Inc.), women were depicted engaging in strength-building activities that develop muscle. The presence of women featured in the Journal also expanded at this time (Knapp 2015a). 


\section{Analyses of CrossFit participants' lived experiences}

Researchers have yet to conduct an in-depth exploration of the embodied experiences of CrossFit participants. More specifically, researchers have not explored how CrossFit may set a context for the development of participants' body images, appearance management practices, and identities. However, Knapp (2015b) recently adopted a critical feminist geographical approach and interpretive methods to consider how traditional concepts of gender are influenced by sociospatial practices within the context of a co-ed CrossFit gym co-owned by two bisexual women and populated primarily by female members and coaches. Analyses revealed that the female participants experienced the CrossFit box as a space that both challenged and reinforced conventional (i.e., heteronormative) notions of masculinity and femininity. For instance, Knapp argued that traditional notions of gender were subverted in that female participants were encouraged "to move beyond the socially acceptable goals of firming and toning and [to] push their bodies to become strong, powerful, and fit" (p. 52), although not necessarily within the context of a traditionally masculine model, as the CrossFit space was experienced as an encouraging one. Encouragement took many forms, including support for doffing one's shirt to display one's abdominal muscles, which some participants framed as a display of confidence. The lack of mirrors in the CrossFit space also shifted women's focus away from what their bodies looked like to how they could perform, affording them the opportunity to engage in transgressive forms of femininity. And, the mere fact that neither the workout routines nor the workout spaces in the gym were sexed was experienced by the female participants as an opportunity for staging resistance against heterosexist biases. In other ways, however, the CrossFit box was experienced as reinforcing traditional notions of femininity; women were whistled at when running in public spaces, and equipment used for work-out routines differed for men and women (e.g., different weights were prescribed for men and women), which participants experienced as reinforcing an essentialist understanding of gender and a "glass ceiling" for female CrossFitters (p. 50).

Knapp's (2015b) work provides some incipient insights into women's experiences related to gender, appearance, and the body within the context of one CrossFit box owned by two women, employing many female coaches, and attracting a largely female membership. However, her work does invite additional research considering the gendering of CrossFit spaces that are not owned and operated exclusively by women ${ }^{1}$ and that are not patronized largely by women. That is, what are female CrossFitters' embodied experiences like in these spaces? Are female CrossFitters who work out in these spaces still able to stage some resistance against hegemonic norms of femininity, particularly given that the culture of the sport has been said to reinforce such norms, at least within its promotional literature? Further, Knapp's work does not examine how embodied experiences within the CrossFit box may shape realities "beyond the box," including how female CrossFitters appraise their bodies, which ideals they aspire to, and how they present themselves and manage their appearances, appetites, and diets in various contexts. Such issues are critical to explore, as prior work suggests that female athletes' experiences of their bodies may vary dependent upon social context (Becker and Record 2016;

${ }^{1}$ CrossFit coaches, who often double as gym owners, exert a considerable influence upon the perceived climate of CrossFit boxes (Partridge et al. 2014). 
George 2005; Howells and Grogan 2012; Steinfeldt et al. 2013). Thus, with the present work, we aimed to build upon Knapp's work by exploring how women's participation in CrossFit sets a context for their embodied experiences inside and outside of the CrossFit box. The experiences of women who belong to and work out at co-ed CrossFit boxes that are not owned and operated exclusively by women and that are not patronized largely by women were considered. Of particular interest was how women's participation in CrossFit gives rise to varied appearance- and body-related feelings and behaviors, bodily aspirations, and experiences relative to cultural norms of hegemonic femininity. An interpretive approach, which allows for the development of rich understanding of participants' lived experiences-from their perspectives- was adopted (see Denzin and Lincoln 2008).

\section{Methods}

In-depth, face-to-face interviews were conducted with 16 women who participate in CrossFit. To be eligible to participate, participants had to be at least 18 years of age and actively participate in CrossFit as reflected by their membership and regular participation (at least 2 times/week) in a CrossFit box. Participants were recruited from a maleowned, co-ed ( $58 \%$ male, $42 \%$ female) CrossFit box in large urban center in the western United States. This particular box employed five CrossFit coaches, three of whom were male. The male owner of the box hired and trained coaches and also served as the "head coach" at the box, acting as the box manager and creating the WODs for the box. Participants were recruited using several methods, including giving an informational presentation about the study to participants in a women's "transformation" seminar held at the CrossFit box, posting flyers at the CrossFit box, and employing snowball sampling.

Participants ranged in age from 27 to 45 years (mean $=31.8$ years). Fifteen participants identified as Caucasian/White; one participant identified as Hispanic. All participants identified as heterosexual. Participants varied in their body mass indices (BMIs). According to the BMI classifications used by the Centers for Disease Control and Prevention (2015), ten participants were classified as "normal" or healthy" weight, four were classified as "overweight," and two were classified as "obese." However, it should be noted that BMI is not always an accurate indicator of body fat for athletes, as muscle is denser than is fat (Etchison et al. 2011). Ten participants were married, one participant was divorced, three participants were dating, and two participants were single. Participants had been involved in CrossFit for an average of 2.8 years (range 10 months to 6 years). In a typical week, participants engaged in CrossFit work-outs an average of 3.6 times/week (range 2-6 times/week). Selected participant background characteristics are presented in Table 1. In this table and throughout the discussion, participants are referred to by pseudonyms to protect their identities.

Interviews were conducted by the first author at a private location chosen by the participants (e.g., participants' homes). The interviews were conducted face-to-face to gather rich, meaningful data and followed an in-depth, semi-structured approach (Gibson and Brown 2009). Interview questions focused upon female CrossFit participants' (a) experience of CrossFit ideology and culture, (b) body- and appearance-related feelings and behaviors, (c) identity development and negotiation, and (d) negotiation of norms of hegemonic femininity. Questions were framed in an open-ended format. Most 
Table 1 Selected participant background information

\begin{tabular}{|c|c|c|c|c|}
\hline Participant \# & Age & $\mathrm{BMI}^{\mathrm{a}}$ & $\begin{array}{l}\text { Length of time involved } \\
\text { in Cross-Fit }\end{array}$ & $\begin{array}{l}\text { Typical \# of Cross-Fit } \\
\text { Work-outs/week }\end{array}$ \\
\hline Beth & 45 & 22.1; "normal/healthy" & 4.5 years & 2-3/week \\
\hline Amy & 26 & $21 ; "$ normal/healthy" & 2 years & 2-3/week \\
\hline Marsha & 39 & 32.9;"obese" & 2 years & 3/week \\
\hline Nancy & 27 & 21.5;"normal/healthy" & 2.5 years & 3-5/week \\
\hline Ann & 30 & 26.6; "overweight" & 3 years & 3-4/week \\
\hline Kathy & 29 & 27.4;"overweight" & 3 years & 5/week \\
\hline Jo & 27 & 24.2;"normal/healthy" & 3.5 years & 3-4/week \\
\hline Emma & 26 & 21.8;"normal/healthy" & 2 years & 3-4/week \\
\hline Jan & 31 & 24.6;"normal/healthy" & 3 years & 6/week \\
\hline Penny & 31 & 23.6; "normal/healthy" & 6 years & 5/week \\
\hline Rachel & 28 & 21.5;"normal/healthy" & 5 years & 4-5/week \\
\hline Diane & 32 & 20.2; "normal/healthy" & 10 months & 3/week \\
\hline Julie & 40 & 25.8; "overweight" & 3.5 years & 3-4/week \\
\hline Stephanie & 39 & 25.7; "overweight" & 1.5 years & 3-4/week \\
\hline Claire & 27 & 24.7;"normal/healthy" & 1 years & 2/week \\
\hline Linda & 32 & 31.6;"obese" & 2 years & 3/week \\
\hline
\end{tabular}

Some participant demographics are not included in this table so as to protect participant identity

a According to the Centers for Disease Control and Prevention (2015), adults with a BMI below 18.5 are "underweight," those with a BMI ranging from 18.5 to 24.9 are of a "normal" or "healthy" weight, those with a BMI ranging from 25.0 to 29.9 are "overweight," and those with a BMI of 30.0 or higher are "obese."

interviews lasted approximately $1 \mathrm{~h}$. All interviews were digitally recorded, and sampling continued until saturation in meaning was achieved.

All interviews were transcribed verbatim and were divided into meaningful segments or text units (Guetzkow 1950). Constant comparison processes (associated with the grounded theory approach) were used to analyze the data (Corbin and Strauss 2008). During the open coding phase, key concepts were identified within the data. These concepts were compared to one another and were grouped under higher order, more abstract concepts (Corbin and Strauss 2008). These concepts formed the basis for the development of a coding guide that was applied to the interview data until the coding categories were saturated (Gibson and Brown 2009; Strauss and Corbin 1990). Axial and selective coding were utilized in the final stages of analysis to search for relationships/patterns within the data and to consider the relevance of existing work to the data (Strauss and Corbin 1990).

The trustworthiness and reliability of the data collection and analysis were established through reflexive journaling and peer review. During each interview, after each transcription, and throughout the open coding process, the first author recorded detailed reflections upon the participants' accounts as well as her own experiences with CrossFit. ${ }^{2}$ These incipient insights served as a starting point for the data analysis. The authors also engaged in dialogue throughout the analysis process to ensure mutual understanding was achieved. Additionally, member checks were used, as needed. Specifically, if

\footnotetext{
${ }^{2}$ With the grounded theory approach, researchers use their own lived experiences to better understand human processes under investigation (Baker et al. 1992). Of relevance here is that the first author has participated in CrossFit for 5 years. On average, she participates in CrossFit work-outs 3 times/week. The second author has not participated in CrossFit.
} 
there were any areas within participants' narratives needing clarification, participants were emailed to confirm the researchers' understanding of the data. Finally, an audit coder (a graduate student with expertise in body image) checked the first author's application of the coding guide to one-fourth the data (i.e. four transcripts, or $25 \%$ of the transcripts). Disagreements in coding assignments were negotiated. Interrater reliability with the audit coder was $90.1 \%$. Interrater reliability was calculated by dividing the total number of agreements in coding decisions by the total number of coding decisions made.

\section{Results and discussion}

Analyses of participants' embodied experiences inside and outside of the CrossFit box revealed a diverse array of lived realities, suggesting that participants' experiences of this cultural space were not of "one piece" (cf., Bordo 1999, p. 204). Participants' experiences coalesced around two overarching themes, around which the following discussion is organized: (a) differing experiences of the CrossFit box community and CrossFit cultural rhetoric and (b) embodied practices. Additionally, within many of these themes-across as well as within participants' accounts-there was evidence of contradiction and/or ambivalence.

\section{Differing experiences of the CrossFit box community and CrossFit cultural rhetoric}

Participants experienced the CrossFit box community and related cultural rhetoricincluding meanings conveyed through interactions with the owner/coaches and CrossFit box members as well as appearances, attitudes, behaviors/regimens promoted within this community-in differing ways. In addition to characterizing the CrossFit box community, participants spoke to the ways in which the culture of the community set a context for the construction of specific meanings about diet, fitness, and appearance.

\section{The CrossFit box community}

Accounts revealed that although several participants experienced the CrossFit box as inclusive, a handful of others felt that the community was rather exclusive. Participants who experienced the box as inclusive spoke to the diversity of the membership and to the owner's/coaches' and members' willingness to embrace people of all skill and athletic capabilities. Conversely, participants who experienced the box as exclusionary perceived the membership of the box to be homogeneous and/or did not feel welcomed in the space.

Participants also spoke about the gendering of the CrossFit box. Consistent with Knapp (2015b), many participants experienced the box as a space to transgress hegemonic norms of femininity by openly displaying traditionally masculine traits such as strength and aggressiveness: “...in the...box....we're pushed to be aggressive, vocal, and strong...It's rewarding...I don't feel like we get the same respect outside of the gym in that way" (Ann, 30 years). Participants who experienced the box as an environment in which to disrupt traditional norms of femininity sometimes also expressed an openness to "try[ing] whatever the guys are doing" (Emma, 26 years), suggesting a mindset that supports the challenging of gendered behavior expectations. 
A few participants also characterized the CrossFit box as a place for women and men to subvert gendered expectations for fitness competencies and achievements. For instance, participants described a practice in which women referenced men's accomplishments during workouts as a gauge for their own accomplishments (and vice versa), resulting in an "undoing" of gendered norms. In other cases, however, participants spoke about the explicit gendering of CrossFit work-out routines and equipment ${ }^{3}$ as creating "equality in opportunity," with everyone having access to "the right equipment" (Emma, 26 years). Participants' readings of these gendering practices as creating parity diverge from prior work in which CrossFit participants have interpreted the gendering of equipment in CrossFit boxes as naturalizing gender differences between men and women and as "reinforcing a glass ceiling" for female CrossFitters (Knapp 2015b, p. 50).

As with Knapp's (2015b) work, several participants-especially those who were older and who were mothers-also described how the culture of the box gave rise to gender hegemony. Of note is that participants' explanations for how this hegemony unfolded diverged from the participants in Knapp's study. These differences in participant experience seem to be due in part to the difference in the gendering of the respective boxes (e.g., gender composition/balance of membership, gender/gender ideology of owner). For instance, Marsha (39 years) noted that some male members of the box exhibited a "good old boy attitude," which caused her discomfort. Participants also experienced unease when they were the only women in their class, noting that they felt "exposed." And, participants described how the prevalence of male members at the gym created a culture that supported competition for male attention (which, at times, undermined women's support of one another) and "drama" around presenting the self as heterosexually attractive. Although participants shared the perception that some female members of the gym dressed to draw attention from the male members-whom they regarded as potential romantic partners-Marsha also noted that the atmosphere of "sexual tension" at the gym prompted her to dress so as to "hide" her body; this finding contrasts with Knapp's, where participants felt empowered doffing clothing. Finally, some participants described how their interactions with the male owner of the box incited feelings of discomfort and discouragement. For instance, Marsha noted that the male owner of the box provided "traditionally masculine" forms of coaching support, attempting to encourage members by making remarks such as, "Come on, suck it up." Marsha found such comments disheartening rather than reassuring. She, along with other participants preferred the gentler and more positive forms of support offered by the female coaches, to whom participants looked as role models.

\section{Diet}

Participants experienced the culture of the CrossFit box as supporting varied ideologies about diet, with most of this diversity in meaning occurring across participants. For instance, selected participants shared that the members of the box were encouraged to pursue freedom in eating and were not "pushed" to adhere to any specific diet. These participants noted that they, rather than coaches, initiated dialogue about diet, and

\footnotetext{
${ }^{3}$ The offering of different work-out routines and equipment for men and women is conventional at CrossFit affiliate boxes.
} 
further indicated that they appreciated the lack of "pressure" and "obligation" to conform to specified dietary norms.

Most participants, however, felt that the box coaches and community emphasized the philosophy, that, in order to see "results", members needed to follow specific dietary regimens to support their CrossFit work-outs. To this end, participants perceived that coaches and the community endorsed specific diets such as Paleo and clean eating, noting that a Paleo/clean eating recipe book was available for purchase on-site and that the box owner frequently invited sponsors of Paleo and clean eating regimens to the box. Participants also remarked that coaches and the owner sometimes promoted an ideology in which members were encouraged to engage in CrossFit workouts as "punishments" for eating "transgressions." As is evident in the following comment, this philosophy made some participants uncomfortable:

I will hear coaches say things like, "I know you guys went out and drank last night, so...you better go hard today."....There was a girl explaining that last night she went out with her friends and they got popcorn, and the encouragement [the coach] was giving [her] was, "Let's work off the popcorn." [The coach] would say things like, "How does that popcorn feel? Sweat it out!" And, I was just like, "Nooo..." (Jan, 31 years)

As compared to participants who did not sense pressure from the box to conform to a specific diet, those who did experience the box as promoting particular ways of eating were more likely to report a personal history with food restriction for reasons of aesthetics and athletic performance, and as such, they may have been more sensitive to rhetoric specific to diet. Perhaps owing in part to their history with food restriction, these participants also were more likely to have BMIs in the normal/healthy weight range. Here, we do not intend to imply that body weight/BMI is a product only of dietary habits, as we acknowledge that a wide range of factors contribute to body weight, including dietary habits, exercise habits, sleep patterns, as well as other factors beyond one's personal control, such as genetics, age, stress, biological/physiological factors, and health issues (Campos et al. 2006).

\section{Fitness}

Accounts revealed that participants experienced the culture of the CrossFit box as promoting differing ideologies surrounding fitness, with differences in meaning observed across and within participant narratives. Many participants-especially those who felt confident in their CrossFit skills-experienced fitness rhetoric within the box to be empowering. These participants shared that the coaches and owner focused on form and technique of weight lifting moves, never pushing members beyond their limits and working around members' injuries, which, they felt, created a safe environment for members. These participants also noted the willingness of coaches to work with members to achieve any goal set and/or to frame failure to achieve goals positively:

[The head coach/owner is] really good about...challeng[ing] students...to confront failure...not as failure in and of itself, but as... by failing at $A$, you were able to do $B$. (Linda, 32 years) 
Several other participants described the culture of the gym-and in particular, interactions with coaches and members-as exerting pressure to maintain physical and aesthetic gains and to build strength. In this vein, Amy noted that coaches and members frequently remarked about the members' "development of musculature" and warned about the loss of gains by participants who took a break from CrossFit while out of town (Amy, 26 years). Some participants also felt that coaches contributed to a mindset that members should always try to "lift heavier" (Beth, 45 years). This emphasis on strength prompted Amy (26 years) to question why mobility was not also promoted at the box, as she believed the singular focus on strength butted against CrossFit's promotion of functional fitness, “...Your body is strong, but you can't touch your toes, and what's the point of that?". Beth expressed somewhat mixed or ambivalent feelings about the box's approach to strength training, at one point suggesting that the coaches "do health and fitness the right way, "not overdoing it," and at another juncture, observing that CrossFit workouts demanded overexertion that negated the notion of "not overdoing it" and the ideology of "functional fitness" often associated with CrossFit:

CrossFit... has a mindset [that] you should try to lift heavier weight... so there is a bit of a struggle to go, "No, I don't need to lift that much weight because, oh, I have to do other things today, like, Oh! I might want to go shovel dirt in my garden, and I don't want to be so sore that I can't." So... sometimes, that balance concept is lost. I'm here to be healthy so the rest of my life...I'm not just here for that hour, dumping it all. (Beth, 45 years)

Compared to other participants, those who described the fitness culture at the box as a source of pressure were less likely to be confident in their CrossFit abilities and were more likely to engage in CrossFit to buttress their progress in another sport (e.g., aerial dance) or to support their health. As such, the fitness culture of CrossFit may have conflicted with their personal ideologies surrounding physical activity (e.g., as reflected in Beth's comments above).

\section{Appearance}

Views about the box's values around the issues of appearance and the body coalesced around varied perspectives, with different participants embracing differing views. For instance, many participants (especially those who embraced their bodies) characterized the box as promoting an inclusive ideal that deemphasized physical appearance and that emphasized performance, or the "score on the board" (Jo, 27 years). As evidence of this claim, participants often noted that the box's female membership embodied women of all different shapes and sizes, all of whom could "do the same workout...regardless of physical appearance" (Ann, 30 years). Thus, among these members, the box was viewed as a judgement-free zone where members were not pushed to fit a "specific mold" (Diane, 32 years).

Several other participants, however, described the CrossFit box as promoting an appearance-focused ideal that underscored the "look" of female strength and muscularity. These participants spoke about how coaches and members at the box promoted the ideal of a "strong-appearing" (i.e., fit, "in shape," muscular) female body. Some participants perceived that the box's support of female muscularity represented a tolerance for 
the disruption of expectations of ideal femininity (cf., Knapp 2015a): [At the box, we are not]...'looked down upon [for having] muscles or to be...bigger than what's common in society" (Kathy, 29 years).

Still a few other participants shared the perception that the box maintained norms of ideal femininity (cf., Knapp 2015a; Washington and Economides 2015), featuring "all the pretty people" (Marsha, 39 years) on the box website. Among these participants, a particular female coach was regarded as exerting considerable pressure to "stay tiny," and to thereby meet cultural norms of hegemonic femininity (e.g., thinness):

[There's a certain coach who]...has a popular blog and Instagram account...she was a competitive regional athlete and...she gave up competing and lost...like $40 \mathrm{lb} . .$. her whole thing is, she says, "I'm not going to lift heavy because I want to stay little." ...

There's this constant tension in the gym where it's like, people are like, "You know, I'm going to go light today because I want to stay tiny." (Jan, 31 years)

\section{Embodied practices}

Participants also spoke at length about their embodied experiences and practices within and outside of the CrossFit box. In many instances, these experiences and practices seemed to be produced in part by participants' immersion within the CrossFit culture. As with participants' experiences of the box culture, their embodied experiences and practices varied across the sample.

\section{Ideals aspired to}

Participants aspired to varied bodily ideals, with even individual participants sometimes acknowledging an openness to differing ideals. In some but not all cases, the ideals participants strived to achieve aligned closely with those promoted within the box culture. For instance, several participants described aspiring to an "athletic" ideal. Some of these participants defined this ideal primarily by the achievement of physical strength. However, some participants also sought to have their athletic achievements "reflected in how [they] look" (Stephanie, 39 years), aspiring to a visually strong, or muscular, body:

So I like looking muscular, so I like to train and I like being proud of like my accomplishments of getting stronger. And, if the side effect of me getting stronger is me getting more muscular, then that's my ideal of what I want to look like. (Penny, 31 years)

In addition to referencing the possibility of "women with muscle [as] beautiful" (Penny, 31 years), these participants spoke about the role of CrossFit in normalizing female muscularity.

A few participants-particularly those who were older or who were mothers-aspired to a health-focused ideal. Although this body ideal was not specifically identified as promoted by the box culture, participants did speak to the box's endorsement of healthfocused eating regimens (e.g., "clean eating"). Participants embracing the ideal of health placed emphasis upon taking care of themselves physically and emotionally so that they could be "healthy and functional" (Beth, 45 years) as well as content and emotionally balanced. In contrast to many Western cultural discourses about the body (cf, Shilling 
2003), participants embracing the health ideal did not conflate issues of health and physical appearance (e.g., the notion that a healthy body looks a certain way).

A handful of the participants-particularly younger women in the sample and those with BMIs in the normal/healthy weight range ${ }^{4}$-made comments suggesting that they aspired to an ideal that was influenced by culturally privileged forms of femininity-an ideal that was reported as promoted within the box culture. For instance, Nancy (27 years) discussed wanting to "fit the slender ideal" especially during summer, when she would be "on display" at the pool. Participants also spoke of aspiring to look like "models and celebrities who are not carrying any extra weight" (Amy, 26 years). In other cases, participants who had at one juncture in their narratives prioritized aspirations of being "strong and capable" or "healthy" (even over being thin) acknowledged their concurrent longing to be slender. These findings provide some additional support for prior work suggesting that women who participate in sports may eschew fat (George 2005).

Finally, a couple of participants shared the perspective that women should not be compelled to strive for any given ideal, but should be free "just [to be] happy with who they are and what they look like" (Claire, 27 years). These participants regarded all women as "capable, regardless of appearance" (Stephanie, 39 years) (an ideology that some participants perceived as reflected by the box's physically diverse female membership), and felt that confidence, not appearance, defined beauty.

\section{Bodily appraisals}

Participants' appraisals of their bodies varied across and within participant accounts. Many participants described comfort with and respect for their body and its capabilities, including their strength, which they regarded as a source of pride and as part of their persona. They also spoke about how their participation in CrossFit supported their acceptance of their bodies as well as a shift in "mindset away from what [their bodies] look like to what [their bodies] can do" (Amy, 26 years) (cf., Eklund and Masberg 2014; Krane et al. 2004), noting:

"[CrossFit] helps you realize that your body is functional...maybe my body is not exactly what I want it to look like, but it did exactly what I wanted it to do [in the workout], and that's more important" (Penny, 31 years)

In contrast, a few participants, particularly those who fell within the normal/healthy BMI range, disclosed that they felt rather conflicted about their bodies. Typically, this concern stemmed around anxiety about being "too bulky or boyish" (Jo, 27 years), which complicated participants' capacity to fully meet cultural expectations of femininity and which echoes the key dilemma of the "paradox of the physically active female body" (Cole 1993; Krane et al. 2004, p. 316). It seems possible that women in the nor$\mathrm{mal} /$ healthy BMI range were most likely to experience conflict relative to the paradox of the physically active female body because they also were more inclined to aspire to

\footnotetext{
${ }^{4}$ That these participants were more likely to be younger may explain the fact that they also were more likely to have lower BMIs as compared to the rest of the sample; for women, BMI increases with age (Williamson 1993). Also, although speculative, it is possible that women with lower BMIs were more likely to aspire to the thin ideal as compared to their heavier counterparts within the sample because they saw this ideal as within more "ready reach" (i.e., they identified within this ideal) (cf., Smeesters et al. 2010).
} 
an ideal that aligned with culturally privileged forms of femininity/the thin female ideal. Frequently, others outside of the box offered challenging reviews that fueled such concerns and that left participants ambivalent-feeling simultaneously self-conscious about not meeting cultural ideals of femininity and wanting to continue their engagement in CrossFit and to appreciate their bodies for their functional capabilities. Beth, whose husband made known to her that she was "getting too big," discussed the difficulty inherent in trying to identify a "sustainable body type" in order for "society [to] accept you on both sides... [so that] you're not too bulky and you're not too small" (45 years). Other participants, too, shared in this sense of conflict about participating in CrossFit and negotiating a body of the "right" size and degree of muscularity:

...Whatever happens to my body by doing [CrossFit] I will appreciate it...that's the attitude I want to have, but at the end of the day... I really...struggle with...just like... I see people who do yoga... and I'm like, that also looks really good and they fit in clothes [laughs]...I think now my feelings about my body are a lot more complicated, like I think I'm awesome... At the same time, I look a lot different than I used to. (Jan, 31 years)

Part of the "complexity" that Jan speaks to in the comment above seems to be the notion that her satisfaction with her body is uneven, perhaps varying across context (cf., Beckner and Record 2016; George 2005; Howells and Grogan 2012; Steinfeldt et al. 2013). She expresses a desire to embrace her "CrossFit body/self"- and seems to do so to some extent, noting that she is "awesome." At the same time, however, she expresses a longing to look different that she currently does (at least some of the time), particularly relative to "fitting in clothes," suggesting that she is perhaps less satisfied with her body/ self in non-CrossFit contexts.

\section{Appetites and diets}

When participants characterized their appetites and diets, they frequently discussed how their engagement in CrossFit had given rise to various changes in their diets. Several participants described how their involvement in CrossFit had prompted an interest in "eating clean"-or consuming what they identified as "real food" that was not processed and that they had grown or cooked themselves. Some participants talked about "experimenting" with various diet regimens (e.g., Paleo) and/or removing or adding food from or to the diet to see what made them "feel best." A couple of participants noted that their engagement in CrossFit had encouraged them to adopt a more "relaxed" approach to eating and to abandon their previous tendencies toward food restriction. One of these participants described her evolution from rather severe food restriction, to trying the Paleo diet, to adopting a more inclusive approach to eating:

Honestly, after...restricting almost all food groups, I learned a lot from doing Paleo.... I didn't eat any meat for like 7 years... and once I started eating meat I just felt like a thousand times better... although I don't think that eating Paleo is a healthy way to live your life...I've...been with my husband for 8 years, and this is the first year that we've been able to eat food together. We cooked two separate meals every night because I felt like I had like this approved Paleo food list...And it's been so wonderful to be able to go out to dinner with him... (Jan, 31 years) 
Many participants discussed how their participation in CrossFit prompted changes in how they regarded the relationship between food and fitness. Most frequently, participants remarked that their participation in CrossFit had underscored for them the notion that what they ate impacted their athletic performance. Accordingly, participants discussed the notion of "eating to perform," which frequently entailed the need to increase their food consumption to "to fuel for a workout" (Rachel, 28 years): "[I've experienced a] shift from thinking about calories to thinking about...[food as]...fuel, if I don't eat enough I'm just going to never get better, because my muscles are going to be super tired all the time" (Emma, 26 years).

Finally, although none of participants provided accounts of disordered eating, some did acknowledge participating in CrossFit workouts as a means by which to earn food and/or negate overeating, similar to findings suggesting that female athletes may be at higher risk for controlling their weight through dieting, fasting, and excessive exercising (cf., Anderson and Petrie 2012; Crissey and Honea 2006; George 2005). In this vein, Emma (26 years), who also discussed thinking about food as fuel, noted that she felt that she needed to "work extra hard" in CrossFit workouts to earn a beer at the end of class. And, Jo shared that even though she tried to avoid processed foods, if she did "cheat and pig out on ice cream," she would "go to the box and work it off" (27 years). This ideology aligns closely with the notion that one ought to engage in CrossFit workouts as a reaction to eating "missteps"-an ethos that participants described as promoted by the box owner and coaches.

\section{Physical fitness}

Participants shared how their engagement in CrossFit supported various changes in their thoughts about, and participation in, other forms of physical fitness. Many of these shifts in thinking about fitness align closely with intrinsic motives for exercise, ${ }^{5}$ or those that focus upon revitalization of the self and/or personal enjoyment and fulfillment; such motivations have been linked with psychological well-being (Markland and Ingledew 1997). For instance, several participants described, how, since becoming involved in CrossFit, they had come to see the purpose of physical fitness as the nurturing of a skill set or the building of physical capacity rather than the development of bodily aesthetics such as "wanting to be skinny" (Jo, 27 years). Similarly, participants mentioned that they no longer worked out with the goal of "burn[ing] calories," but instead, aimed to relieve stress and "feel strengthened" (Ann, 30 years) (cf., Knapp 2015b). Several participants also spoke about how CrossFit expanded their understanding of being "fit and healthy" to include the notions of seeking balance in one's life (e.g., meaning work hard-at work or at the box-but also make time for "play" activities) and of being physically active on a daily basis. And, a few participants described participating in other fitness activities to complement their success in CrossFit as well as speaking to how their CrossFit participation supported their engagement in other physical activities such as running, yoga, and Pilates (e.g., by increasing their endurance). A couple of participants, however, noted how the intense physical demands of regular CrossFit participation precluded their

${ }^{5}$ Conversely, extrinsic motivations for exercise are prompted by a desire to change appearance (Markland and Ingledew 1997). 
involvement in other forms of physical fitness. For instance, Julie remarked that she was "tired after 4 days of CrossFit," and therefore, was unable to partake in other physical activities that she formerly had enjoyed, such as running.

\section{Appearance management}

Participants, particularly those with a normal/healthy BMI, also shared how their involvement in CrossFit had impacted their grooming behaviors. For one participant, in particular, involvement in the sport translated to heightened attention to grooming; Jo (27 years) described an awareness of a gaze at the box-with others "looking" at her bodily appearance. She further articulated how this perception motivated her to shave her legs "if she was going to the gym" (Jo, 27 years), as "legs look sexier when they're hairless" (27 years). However, other participants described how their immersion in the sport of CrossFit had prompted them to become less invested in their appearance such that they curtailed some aspects of their grooming routines:

It's fairly safe to say that [spending less time on my appearance] is probably a function of my time with CrossFit in terms of the emphasis...that I place on that now...I don't really wear make up any more...I just don't care. (Amy, 26 years)

Participants also gave accounts of changes to their dressing patterns or personal wardrobe habits since participating in CrossFit. A handful of participants described changes to their personal style, noting that CrossFit spurred them to appreciate functional and comfortable clothing and to purchase more activewear, reflecting the important role of the sport in their lives. A few participants discussed how their participation in the sport had increased their confidence in their bodies, and thus, their willingness dress in ways that drew attention to the body. However, as noted, Marsha (39 years) did not feel comfortable exposing certain aspects of her body at the box owing to the sexual tension there, and as such, dressed to camouflage or hide her body when going to the gym. Finally, several others described having to purchase new clothing and/or to re-learn to dress their bodies after becoming involved in CrossFit, owing to changes in their body shape and composition (e.g., losing weight or gaining muscle). In this vein, Jan (31 years), a retired professional runner who weighed $115 \mathrm{lb}$ when she started CrossFit, reported that she gained $10 \mathrm{lb}$ during her first three months of her involvement in the sport. At the time of her interview, she weighed $145 \mathrm{lb}$. This weight gain spurred mixed feelings about dressing herself; although she remained "really proud of [her] athletic accomplishments" and "want[ed] her body to support her athletic pursuits," it had become a "battle" to find street clothes that fit and that made her feel confident about her appearance, as her "body has changed so much" since starting CrossFit. Here, then, we see evidence of the role of social context in shaping participants' feelings about their bodies (i.e., athletic versus nonathletic contexts) as well as the way in which female CrossFitters may find it tricky to balance success in their sport and the management of a convincing presentation of femininity (cf., Beckner and Record 2016; George 2005; Howells and Grogan 2012; Krane 2001; Steinfeldt et al. 2013). 


\section{Gender}

In addition to characterizing the gendering of the CrossFit box, participants revealed how their participation in CrossFit had shaped their sense of themselves as gendered beings. Frequently, participants observed that CrossFit engagement had afforded them the opportunity to "disrupt traditional gender stereotypes" (Emma, 26 years; Diane, 32 years) by presenting an "alternative" (Amy, 26 years) for what women can be, meaning that women can be strong and athletic rather than being measured against the hegemonic ideal. Participants embraced the perceived opportunity presented within the box to display these traditionally masculine traits (e.g., strength, athleticism) and to deconstruct the gender stereotype that men are (necessarily) stronger than women:

Um, there's like so many women in the gym that are stronger than a ton of the men in the gym...I think society...constantly tells us like men are stronger than us, and blah, blah, blah, and we can't be as strong as a man. And granted, if that man tried hard, he could be stronger than me, but in that moment, he's not stronger than that girl that's next to him. You know, and I think that's kind of a cool thing for women to see...(Penny, 31 years)

Insomuch as they were able to transgress stereotypes of women as weak, several participants expressed that they gained a sense of empowerment through their engagement in CrossFit. For instance, participants noted how the act of lifting heavy weights "strengthens feminine resilience and takes away the weakness of the feminine" (Beth, 45 years) as they felt strong physically and "within themselves" (Ann, 30 years), both in the box and out in their communities. Empowerment also was attributed to feeling as though they could "hold their own" (Ann, 30 years) in the box and in society, further creating a sense of equality between men and women.

Interestingly, several participants gave accounts suggesting that CrossFit may shape women's and men's gendered and embodied realities in differing ways. For example, one participant spoke to the idea that although CrossFit may be empowering for women, providing recognition for what they could do athletically, the culture of the sport may place a body image burden on men:

...I think it's given women... more recognition in athletics and what women are capable of...I also think it's made things for males much more challenging with their body image. You know, no one really talks about male body image, but the rate of negative body image in men and eating disorders is very high, and I think CrossFit probably contributes to that; and so, it's made it easier for women, but I think it's hindering men, as well. Um, so it's kind of an interesting circle of things, how that works, where like, women are feeling better and empowered, and men, maybe not so much.

(Rachel, 28 years)

\section{Identity}

Identity can be conceptualized as the "self in context" or the situated self. All of our identities, taken together, constitute the self (Kaiser 1997, p. 96). In considering how CrossFit gave rise to the development of their selves and body images, participants spoke to the way in which participation in this sport prompted changes in their personal/individual 
and their relational identities. Personal/individual identities are linked to traits or personality characteristics (Stryker 2007), whereas relational identities are associated with roles and behavioral expectations (Stryker and Burke 2000).

For instance, several participants noted that their engagement in CrossFit amplified their confidence and feelings of empowerment (i.e., personal and individual identities) beyond the CrossFit box. Participants gave accounts of confidence outside of the box, such as "speaking up in work meetings" (Jo, 27 years) and having the confidence to speak to strangers or to "not be as shy" (Penny, 31 years). Participants attributed these feelings of increased confidence to "stepping out of their comfort zones" (Penny, 31 years) in the box and to interacting with other members during their workouts. A few participants described a deeper understanding of their personal fortitude based upon what they had learned about themselves through their engagement in CrossFit workouts, which Amy (26 years) characterized as a deepened "mental, physical, and emotional resilience" to take on any challenge and not give up.

A handful of participants also spoke to the ways in which their involvement in CrossFit supported their identities as athletes (i.e., relational identity). One participant noted she "never considered [herself] an athlete before [CrossFit]" (Jo, 27 years), but that after participating in CrossFit for three and a half years, she had begun to identify as an athlete and to feel that she had better control over how her body moved physically. Other participants who were former athletes reported they felt that CrossFit had helped them to restore their athletic identities. In this vein, Julie noted that participating in CrossFit that "gave her back her athletic identity" (40 years) that she felt she had lost. Similarly, Jan, a former professional runner, shared that CrossFit helped her rise out a "funk" by providing her a "competitive outlet" (31 years) similar to that which she had enjoyed during her running career.

\section{Conclusion}

This interpretive study fills a gap in the literature by contributing insights into how women's participation in CrossFit sets a context for their embodied experiences, inside and outside of the box. In particular, the present work illuminates how women experienced the culture of a male-owned, co-ed, CrossFit box and how their immersion and participation in that box culture gave rise to varied bodily experiences and practices, including body/appearance ideals, bodily appraisals, appetites and diets, physical fitness ideologies, appearance management routines, perspectives on gender, and identity development. Participant narratives revealed diverse lived realities across accounts as well as some evidence of contradiction or ambivalence within individual accounts.

Across the findings, participants' lived realities-as articulated in their interview narratives - were conceptualized in terms of themes and subthemes relative to their experiences of the CrossFit culture and the embodied practices that this culture supported. These themes can be further understood, perhaps, in the ways that CrossFit culture and their immersion in it fostered both experiences of empowerment as well as experiences of confinement and oppression. For instance, some participants shared accounts of experiencing agency in relation to transgressing norms of gender hegemony by cultivating their physical strength and muscularity, by embracing the functionality of their bodies (cf., Ecklund and Masberg 2014; George 2005; Howells and Grogan 2012; Krane 
et al. 2004) and by celebrating increased confidence in their everyday lives. Thus, findings provide some support for the notion that participation in CrossFit supports "body positive" experiences, similar to women's participation in other sports (cf., Ecklund and Masberg 2014; Krane et al. 2004). At the same time, however, participants described feeling constrained by their immersion in the box or their engagement in CrossFit, noting the pressures to meet the physical demands of the sport, their sense of the coaches' and members' gaze over their bodies, and the sexually-charged culture of the gym. For some, the "paradox of the physically active female body" (Cole 1993; Krane et al. 2004, p. 316) also was a source of anxiety. As such, taken together, findings present a complex picture of the ways in which participation in CrossFit may be experienced by its female participants, a finding that also emerged from Knapp's (2015b) work, albeit not focused upon embodied experiences and practices "beyond the box."

Differences in experience across participant accounts seemed to be explained, in part, by participants' social locations and prior lived experiences, including their ages, BMIs, maternal statuses, gender ideologies, and/or personal histories with diet and physical fitness. ${ }^{6}$ Interpersonal interactions-and participants' reflections upon them-also contributed to differences in experience. As noted, not all of the variation in the findings occurred across participant accounts, however. In some cases, individual participants also described conflicting or mixed feelings-akin to ambivalence or tension-that were prompted by their engagement in CrossFit. For example, instances of ambivalence within participant accounts were observed relative to the fitness ideology promoted by CrossFit coaches and navigation of the "right" amount of female muscularity. It seems possible that some of this variation across or within participant experience could be due, in part, to the fact that CrossFit culture has been found to promote incongruous messages about the femininity and the female body. Both prior work (Knapp 2015a) and the present findings suggest, for instance, that CrossFit culture simultaneously promotes and challenges hegemonic femininity. And, in many cases in the present work, participants' embodied practices seemed to align closely with their perceptions about bodyrelated meanings or values promoted within or by the box culture (e.g., ideas about what one should eat or how one should exercise, ideas about how one should aspire to look).

In addition to characterizing the embodied practices of women who participate in CrossFit, this work sought to build upon existing research by considering how the gendering of the CrossFit space may shape the experiences of female participants in the sport. In both the female-owned and dominated CrossFit space examined by Knapp (2015b) and the male-owned and co-ed Cross-Fit space considered in the present work, participants staged resistance against hegemonic norms of femininity, even in spite of recognizing that the box culture simultaneously perpetuated and challenged such norms. A common path for staging such resistance among participants in both the Knapp study and in the present sample was the display of traditionally masculine attributes, such as strength, aggression, and muscularity. A further comparison of the Knapp (2015b) findings and those from the present study, however, reveals some differences, suggesting

\footnotetext{
${ }^{6}$ Interestingly, differences in participant experience did not appear to be related to length of participant engagement with CrossFit, which conflicts with prior work suggesting that length of sport involvement may set a context for embodied experiences (Sisjord and Kristiansen 2009) and could be considered further in future research.
} 
that some particulars of participants' experiences were shaped by the gendering of box spaces. For instance, participants in the present sample noted feeling "exposed" in male-dominated contexts and were inclined not to reveal their bodies in such contexts, whereas participants in the female-dominated context examined in Knapp's (2015b) work were confident about doffing their shirts. And, selected participants in the present sample characterized the box culture as marked by a "sexual tension" that prompted a sort of "monitoring" of the self/one's appearance, a phenomenon that was not observed among Knapp's participants. Further, participants expressed some discomfort with the male owner of the box due to his masculine coaching style, stressing the importance of female coaches in terms of developing role models for female members. Thus, the gendering of the CrossFit space-relative to the gym ownership and membership-does seem to "matter" when it comes to women's lived and embodied experiences within the box.

Findings from the present research may be of interest to professionals who work in the body image area (e.g., counselors/therapists, sports psychologists, nutritionists). Given the popularity of CrossFit, these professionals may benefit from an increased understanding of some of the various and complex ways that participating in the CrossFit may shape women's embodied experiences and practices; such an understanding could inform their work with female CrossFitters who seek their services. In a similar vein, from an academic perspective, findings from the present work could be incorporated into undergraduate and graduate curricula in disciplines such as apparel and merchandising, gender studies, health and exercise science, nutrition, psychology, and sociology, among others. Students in these disciplines may find themselves in a position to engage with or to serve women who participate in CrossFit and who are seeking support in relation to body image or culturally gendered expectations of behavior. For instance, from a managerial perspective, being aware of the ways in which participation in CrossFit can support-as well as possibly undermine-women's body images and identities can help apparel designers to create CrossFit apparel that reinforces women's self-esteem and that builds their identities in positive ways. Functional and comfortable designs might be developed and marketed to appeal to women's athletic identities. Additionally, designers may wish to consider developing CrossFit apparel that could be worn in various ways in different contexts, affording women varying degrees of body exposure depending upon their comfort level. Findings also suggest managerial implications for CrossFit box owners and coaches, who could use results from this work to inform the development of CrossFit environments that would likely foster more positive body experiences. For example, findings highlight the value of creating CrossFit spaces that support women's subversion of gendered expectations for fitness, that are safe and supportive, and that are not experienced as obliging participants to conform to specified behavioral or body norms. Given that some women described feeling "exposed" in the context of co-ed classes, CrossFit box owners/coaches may wish to consider offering selected classes for women, only. To address some of the body image concerns that may arise among female CrossFit participants, box owners also may be advised to add body image professionals to their staffs and/or to offer educational body image programming for their female participants. 
Findings represent the lived realities of White, heterosexual women who participated in CrossFit activities at a particular box; experiences at other boxes, with their own, distinct cultures, may give rise to differing experiences. Thus, in the future, it will be important to consider how women who represent diverse ethnic/racial backgrounds and sexual orientations experience participation in CrossFit. There is evidence to suggest that ethnic/racial background/identity may shape how girls and women relate to ideals of hegemonic femininity, with women of color embracing a "thicker" body ideal and a more fluid, flexible approach to thinking about the female body that does not hinge upon the achievement of a cultural body ideal (Parker et al. 1995; Wood-Barcalow et al. 2010). Similarly, there is some work to suggest that sexual orientation may shape how women relate to the hegemonic ideal, with lesbian women less focused upon the thin ideal than heterosexual women (Moore and Keel 2003). The present work also was limited in that it did not include the perspectives of the owner or the coaches at the box, but rather, relied upon member accounts to gain an understanding of participant-owner and participantcoach interactions. As such, in the future, it would be valuable to collect first-hand perspectives from various players in the CrossFit box, including the owners and coaches, as well as the members. And, because BMI emerged within this work as a "difference that [frequently] made a difference" (Parker et al. 1995, p. 103), it would be interesting to further explore the role of BMI in shaping women's lived realities of CrossFit. It will be especially important to consider the CrossFit experiences of underweight women, who were not represented within this research. Finally, with future work, it will be important to explore how CrossFit participation sets a context for men's embodied experiences and practices. The participants in the present study observed that CrossFit culture may impose unachievable or unrealistic performance and body ideal expectations upon men, speculating that these expectations could represent a body image burden for men. Thus, it would be valuable to explore this issue from the frame of reference of male CrossFit participants.

Authors' contributions:

MP planned the study, collected the data, took the lead in analyzing the data, and participated in the writing and revision of the manuscript. JPO oversaw the conceptualization/planning of the study, dialogued with MP throughout the data analysis to provide feedback on coding processes and to ensure that mutual understanding was achieved, and participated in the writing and revision of the manuscript. Both authors read and approved the final manuscript.

Competing interests

The authors declare that they have no competing interests.

Ethics approval and consent to participate

The research was approved by the Institutional Review Board of Colorado State University (Protocol 15-6286H), and written, informed consent was obtained from all participants prior to their interviews. The work was carried out in compliance with the Helsinki Declaration.

Publisher's Note

Springer Nature remains neutral with regard to jurisdictional claims in published maps and institutional affiliations.

Received: 26 June 2017 Accepted: 11 December 2017

Published online: 28 January 2018

\section{References}

Andersen, M. L. (1997). Thinking about women: Sociological perspectives on sex and gender. Boston: Allyn and Bacon. Anderson, C., \& Petrie, T. A. (2012). Prevalence of disordered eating and pathogenic weight control behaviors among NCAA division I female collegiate gymnasts and swimmers. Research Quarterly for Exercise and Sport, 83(1), $120-124$. 
Baker, C., Wuest, J., \& Stern, P. N. (1992). Method slurring: The grounded theory/phenomenology example. Journal of Advanced Nursing, 17(11), 1355-1360.

Bartky, S. L. (1988). Foucault, femininity, and the modernization of patriarchal power. In I. Diamond \& L. Quinby (Eds.), Feminism and foucault: Reflections on resistance (pp. 61-86). Boston: Northeastern University Press.

Bartky, S. L. (1990). Femininity and domination: Studies in the phenomenology of oppression. New York: Routledge.

Beckner, B. N., \& Record, R. A. (2016). Navigating the thin-ideal in an athletic world: Influence of coach communication on female athletes' body image and health choices. Health Communication, 31(3), 364-373.

Bordo, S. (1999). The male body. New York: Farrar, Strauss, and Giroux.

Bordo, S. (2003). Unbearable weight: Femininsim, western culture, and the body. Berkeley: University of California Press.

Campos, P., Saguy, A., Ernsberger, P., Oliver, E., \& Gaesser, G. (2006). The epidemiology of overweight and obesity: Public health crisis or moral panic? International Journal of Epidemiology, 35(1), 55-60.

Centers for Disease Control and Prevention. (2015). About adult BMI. Retrieved from https://www.cdc.gov/healthyweight/assessing/bmi/adult_bmi/. Accessed 2 July 2016.

Cole, C. L. (1993). Resisting the canon: Feminist cultural studies, sport, and technologies of the body. Journal of Sport and Social Issues, 17(2), 77-97.

Corbin, J., \& Strauss, A. (2008). Basics of qualitative research (3rd ed.). Los Angeles: Sage.

Crissey, S. R., \& Honea, J. C. (2006). The relationship between athletic participation and perceptions of body size and weight control in adolescent girls: The role of sport type. Sociology of Sport Journal, 23(3), 248-272.

CrossFit, Inc. (2014a). CrossFit theory. Retrieved from http://www.crossfit.com/cf-info/what-is-crossfit.html. Accessed 5 Mar 2015

CrossFit, Inc. (2014b). Forging elite fitness. Retrieved from http://www.crossfit.com/cf-info/what-is-crossfit.html. Accessed 5 Mar 2015.

CrossFit, Inc. (2014c). Training seminars. Retrieved from http://www.crossfit.com/cf-info/what-is-crossfit.html. Accessed 7 Mar 2015.

CrossFit, Inc. (2017). What is CrossFit? Retrieved from https://www.crossfit.com/what-is-crossfit. Accessed 1 May 2017.

Denzin, N. K., \& Lincoln, Y. S. (2008). Introduction: The discipline and practice of qualitative research. In N. K. Denzin \& Y. S. Lincoln (Eds.), The landscape of qualitative research (pp. 1-44). Los Angeles: Sage.

DiBartolo, P. M., \& Shaffer, C. (2002). A comparison of female college athletes and nonathletes: Eating disorder symptomatology and psychological well-being. Journal of Sport and Exercise Psychology, 24(1), 33-41.

Eklund, A., \& Masberg, B. A. (2014). Participation in roller derby, the influence on body image. Clothing and Textile Research Journal, 32(1), 49-64.

Etchison, W. C., Bloodgood, E. A., Minton, C. P., Thompson, N. J., Collins, M. A., Hunter, S. C., et al. (2011). Body mass index and percentage of body fat as indicators for obesity in an adolescent athletic population. Sports Health, 3(3), 249-252.

George, M. (2005). Making sense of muscle: The body experiences of collegiate women athletes. Sociological Inquiry, 75(3), 317-345.

Gibson, W. J., \& Brown, A. (2009). Working with qualitative data. London: SAGE.

Glassman, G. (2002). Foundations. The CrossFit Journal. Retrieved from http://journal.crossfit.com/2002/04/foundations.tpl. Accessed 5 June 2016.

Glassman, G. (2003). Benchmark Workouts. The CrossFit Journal, 13(1), 1-5. Retrieved from Sept http://journal.crossfit. com/2003/09/benchmark-workouts-by-greg-gla.tpl. Accessed 5 June 2016.

Greenleaf, C., Petrie, T. A., Carter, J., \& Reel, J. J. (2009). Female collegiate athletes: Prevalence of eating disorders and disordered eating behaviors. Journal of American College Health, 57(5), 489-496.

Grogan, S. (2008). Body image: Understanding body satisfaction in men, women, and children. New York: Routledge.

Guetzkow, H. (1950). Unitizing and categorizing problems in coding qualitative data. Journal of Clinical Psychology, 6(1), $47-58$.

Hall, M. A. (1996). Feminism and sporting bodies: Essays on theory and practice. Champaign: Human Kinetics.

Holliday, R., \& Hassard, J. (2001). Contested bodies: An introduction. In R. Holliday \& J. Hassard (Eds.), Contested bodies (pp. 1-17). New York: Routledge.

Howells, K., \& Grogan, S. (2012). Body image and the female swimmer: Muscularity but in moderation. Qualitative Research in Sport, Exercise, and Health, 4(1), 98-116.

Kaiser, S. B. (1997). The social psychology of clothing (2nd ed. rev.). New York: Fairchild.

Knapp, B. A. (2015a). Gender representation in the CrossFit Journal: A content analysis. Sport in Society, 18(6), 688-703.

Knapp, B. A. (2015b). Rx'd and shirtless: An examination of gender in a CrossFit box. Women in Sport and Physical Activity, 23(1), 42-53.

Krane, V. (2001). We can be athletic and feminine, but do we want to? Challenging hegemonic femininity in women's sport. Quest, 53(1), 115-133.

Krane, V., Choi, P. Y. L., Baird, S. M., Aimar, C. M., \& Kauer, K. J. (2004). Living the paradox: Female athletes negotiate femininity and muscularity. Sex Roles, 50(5/6), 315-329.

Lovell, T. (1995). Introduction. In T. Lovell (Ed.), Feminist cultural studies (Vol. 1, pp. xiv-xxix). Aldershot: Edward Elgar Publishing.

Markland, D., \& Ingledew, D. K. (1997). The measurement of exercise motives: Factorial validity and invariance across gender of a revised exercise motivations inventory. British Journal of Health Psychology, 2(4), 361-376.

Markula, P. (1995). Firm but shapely, fit but sexy, strong but thin: The postmodern aerobicizing female bodies. Sociology of Sport Journal, 12(4), 424-453.

McDermott, Lisa. (2000). A qualitative assessment of the significance of body perception to women's physical activity experiences: Revisiting discussions of physicalities. Sociology of Sport Journal, 17(4), 331-363.

Milligan, B., \& Pritchard, M. (2006). The relationship between gender, type of sport, body dissatisfaction, self-esteem, and disordered eating behaviors in division I athletes. Athletic Insight, 8(1), 32-46.

Moore, F., \& Keel, P. K. (2003). Influence of sexual orientation and age on disordered eating attitudes and behaviors in women. International Journal of Eating Disorders, 34(3), 370-374. 
Ozanian, M. (2015). How CrossFit because a \$4 billion brand. Retrieved from http://www.forbes.com/sites/mikeozanian/2015/02/25/how-crossfit-became-a-4-billion-brand/\#62eff53378c1. Accessed 5 June 2016.

Parker, S., Nichter, M., Nichter, M., Vuckovic, N., Sims, C., \& Ritenbaugh, C. (1995). Body image and weight concerns among African American and White adolescent females: Differences that make a difference. Human Organization, 54(2), 103-114.

Partridge, J. A., Knapp, B. A., \& Massengale, B. D. (2014). An investigation of motivational variables in CrossFit facilities. The Journal of Strength \& Conditioning Research, 28(6), 1714-1721.

Rally Fitness. (2017). The business of CrossFit: An update on new market research. Retrieved from https://rallyfitness.com/ blogs/news/the-business-of-crossfit-an-update-on-new-market-research-2017. Accessed 1 May 2017.

Rishe, P. (2012). Froning and Thorisdottir repeat CrossFit titles as games growth continues while eyeing greater media distribution. Retrieved from http://www.forbes.com/sites/prishe/2012/07/20/froning-thorisdottir-repeat-crossfittitlesas-games-growth-continues-with-eyeing-greater-media-distribution. Accessed 5 June 2016.

Ritter, E. (2014). By the numbers: The growth of CrossFit. Retrieved from http://www.channelsignal.com/fresh-signals/bythe-numbers-the-growth-of-crossfit. Accessed 5 June 2016.

Shilling, C. (2003). The body and social theory (2nd ed.). Thousand Oaks: Sage.

Sisjord, M. K., \& Kristiansen, E. (2009). Elite women wrestlers' muscles: Physical strength and a social burden. International Review for the Sociology of Sport, 44(2-3), 231-246.

Smeesters, D., Mussweiler, T., \& Mandel, N. (2010). The effects of thin and heavy media images on overweight and underweight consumers: Social comparison processes and behavioral implications. Journal of Consumer Research, 36(6), 930-949.

Smolak, L., Murnen, S. K., \& Ruble, A. E. (2000). Female athletes and eating problems: A meta-analysis. International Journal of Eating Disorders, 27(4), 371-380.

Steinfeldt, J. A., Zakrajsek, R. A., Bodey, K. J., Middendorf, K. G., \& Martin, S. B. (2013). Role of uniforms in the body image of female college volleyball players. The Counseling Psychologist, 41(5), 791-819.

Strauss, A., \& Corbin, J. (1990). Basics of qualitative research (1st ed.). Newbury Park: Sage.

Stryker, S. (2007). Identity theory and personality theory: Mutual relevance. Journal of Personality, 75(6), 1083-1102.

Stryker, S., \& Burke, P. J. (2000). The past, present, and future of an identity theory. Social Psychology Quarterly, 63(4), 284-297.

Tao, D. (2012). The ultimate guide to CrossFit lingo [Blog Post]. Retrieved Feb 16, 2012, from http://greatist.com/fitness/ ultimate-guide-crossfit-lingo.

Ussher, J. M. (1997). Fantasies of femininity: Reframing the boundaries of sex. New Brunswick: Rutgers University Press.

Washington, M. S., \& Economides, M. (2015). Strong is the new sexy: Women, CrossFit, and the postfeminist ideal. Journal of Sport and Social Issues, 40(2), 1-19.

What is CrossFit? (2012). Retrieved from http://community.crossfit.com/what-is-crossfit. Accessed 5 June 2016.

Williamson, D. F. (1993). Descriptive epidemiology of body weight and weight change in US adults. Annals of Internal Medicine, 119(7), 646-649.

Wood-Barcalow, N. L., Tylka, T. L., \& Augustus-Horvath, C. L. (2010). "But I like my body": Positive body image characteristics and a holistic model for young adult women. Body Image, 7(2), 110-116.

\section{Submit your manuscript to a SpringerOpen ${ }^{\circ}$ journal and benefit from:}

- Convenient online submission

- Rigorous peer review

- Open access: articles freely available online

- High visibility within the field

- Retaining the copyright to your article

Submit your next manuscript at $\boldsymbol{\nabla}$ springeropen.com 